\title{
ASSESSMENT OF THE RESISTANCE TO EXTERNAL FACTORS OF LOW-DENSITY POLYETHYLENE MODIFIED WITH NATURAL FILLERS
}

\author{
Karolina Głogowska' ${ }^{1}$, Łukasz Majewski' ${ }^{1}$ Ivan Gajdoš², Gerhard Mital' \\ 1 Lublin University of Technology, Faculty of Mechanical Engineering, Department of Polymer Processing, 36 \\ Nadbystrzycka Street, 20-618 Lublin, Poland, e-mail: k.glogowska@pollub.pl, I.majewski@pollub.pl \\ 2 Technical University of Košice, Faculty of Mechanical Engineering, Institute of Technologies and Management. \\ Mäsiarska 74, Košice 040 01, Slovak Republic, e-mail: ivan.gajdos@tuke.sk \\ 3 Technical University of Kosice with a seat in Prešov, Faculty of Manufacturing Technologies, Department of \\ Automobile and Manufacturing Technology, Bayerova 1, 08001 Prešov, Slovak Republic
}

Received: 2017.07.20

Accepted: 2017.11.01

Published: 2017.12.05

\begin{abstract}
The study reports the results of investigation of basic processing and thermal properties of low-density polyethylene modified with two types of natural filler: wheat bran and pumpkin seed hulls, their content ranging from 5\% to $15 \%$ relative to the matrix. In addition, physical properties of the produced granulates are determined, i.e. the relationship between their density and the applied contents of the tested fillers. Furthermore, the study reports the results concerning longitudinal shrinkage, abrasion resistance and cold water absorption of injection molded tensile specimens.
\end{abstract}

Keywords: natural filler, low-density polyethylene, injection molding

\section{INTRODUCTION}

Growing interest in environment protection resulted in numerous studies devoted to advanced materials made of natural raw materials, such as polymer-matrix composites. The production of materials based on renewable and natural waste materials has become the area of interest for many scientists all over the world dealing with materials engineering and polymer processing. Compared to the widely popular mineral filler and glass and carbon fibers, the addition of natural fillers and fibers to the polymer matrix can be more beneficial, owing to their low cost, low density and environmental friendliness, due to rapid biodegradation $[5,8,12]$.

Increased use of natural materials in producing composite materials has led to the creation of a new class of materials called biocomposites. This term refers to materials in which at least one phase, i.e., matrix or reinforcement / filler, is made of natural materials [8]. One example of such materials are plant fibers which, depending on the plant species, can be produced from pips, stems, leaves or fruit. Composite materials are produced using fibers made from stems and leaves, e.g., wood, cotton, wool, silk, kenaf, etc. [5, 8]. Fillers either naturally occur in a form of fine particles or are subjected to grinding. In the literature of the subject one can find numerous examples of natural fillers, including rice bran [16], banana powder [14], argan nut shell [5], vanilla [9], wood powder [4], switch grass [11], and many more.

The selection of a filler type and content must take various factors and parameters into consideration, from disciplines such as chemistry, physical chemistry of polymers, mechanics, rheology, materials engineering, and even processing machinery design $[2,10,17,20]$. With a properly selected filler content, the properties of a given composite material can be shaped as desired. It is, therefore, important to conduct research on new composite materials based on previously unused fillers $[10,17]$. 
The objective of this study is to investigate the effect of two natural fillers: wheat bran and pumpkin seed husks, on selected physical, tribological, processing and thermal properties of lowdensity polyethylene.

\section{EXPERIMENTAL}

\section{Material}

Test specimens were made of powdered lowdensity polyethylene (LDPE) Dowlex 2631.10UE manufactured by the DOW Chemical Company (Schkopau, Germany). This plastic is used for producing thin-walled parts by rotational casting and high dimensional accuracy parts by injection molding. Table 1 lists the properties of the tested polymer after the specifications provided by the manufacturer.

Two types of natural filler were applied. The first was wheat bran (WB), or the outer layers of wheat grain. Bran is a byproduct of milling process in which wheat grain is conversed to clean, white flour. It has the shape of thin flakes which are several millimeters in size. The main ingredient of wheat bran is raw fiber comprising a sum of fibrous substances such as cellulose, lignin and hemicellulose. Apart from that, wheat bran contains phytic acid, oligosaccharides and non-starch polysaccharides as well as small amounts of fats and proteins [19].

The other natural filler used in the tests were pumpkin seed hulls obtained from a company dealing with purification and sales of pumpkin seeds. Hulls are a waste material produced by mechanical hulling and purification of pumpkin seeds. The main component

Table 1. Selected properties of Dowlex 2631.10UE

\begin{tabular}{|l|c|}
\hline \multicolumn{1}{|c|}{ Property } & Value \\
\hline Density $190^{\circ} \mathrm{C} / 2.16 \mathrm{~kg}$ & $0.935 \mathrm{~g} / \mathrm{cm}^{3}$ \\
\hline Melt flow index $\left(190^{\circ} \mathrm{C} / 2.16 \mathrm{~kg}\right)$ & $7 \mathrm{~g} / 10 \mathrm{~min}$ \\
\hline Vicat Softening Point A120 & $115^{\circ} \mathrm{C}$ \\
\hline $\begin{array}{l}\text { Deflection Temperature Under Load, } \\
\text { HDT, B }\end{array}$ & $52^{\circ} \mathrm{C}$ \\
\hline Melting Point & $124{ }^{\circ} \mathrm{C}$ \\
\hline Crystallization Point & 110 \\
\hline Hardness, Shore D & 56 \\
\hline Tensile Yield Stress & 17,8 \\
\hline Ultimate Elongation & 419 \\
\hline
\end{tabular}

of pumpkin seed hulls are mixtures of polysaccharide substances (cellulose, hemicellulose, pectin, gum, slime mold) and non-polysaccharide substances (lignin) [3].

The fillers were first ground to powder using a grain mill. After that, fractions with different particle sizes were separated using a sieve shaker for particle sizing. This led to the production of a fraction with the grain size ranging between $0.2 \mathrm{~mm}$ and $0.4 \mathrm{~mm}$.

\section{Methods and test stand}

The tests were performed on a control batch of molded pieces made of unfilled LDPE and six batches of injection molded pieces with different filler types and contents. Powdered LD-PE was mechanically mixed with wheat bran and pumpkin seed hulls in three different mass concentrations: $5 \% \mathrm{wt}, 10 \% \mathrm{wt}$ and $15 \% \mathrm{wt}$, respectively. The molded pieces were made using a single-screw, double cavity injection molding machine ARBURG ALLROUNDER 320C for producing specimens in compliance with the ISO 527-1:2012 standard. The parameters of the injection molding process were maintained constant for all prepared polymer compositions. The temperatures of individual zones of the plasticizing unit were set as follows: $\mathrm{tI}-130^{\circ} \mathrm{C}$, tII $-135^{\circ} \mathrm{C}$, tIII $-140^{\circ} \mathrm{C}$, tIV $-150^{\circ} \mathrm{C}$, and the temperature of the injection mold was set to $30^{\circ} \mathrm{C}$. The injection time was set to $2 \mathrm{~s}$. After that, the molded piece in the in mold was subjected to cooling for $30 \mathrm{~s}$.

The properties of the specimens of filled polyethylene blends were examined using the following methods. Density was determined with a pycknometer in compliance with the ISO 3923-1:2010 standard. Wear resistance was measured by the Shopper-Schlobach method according to the procedures formulated in the ISO 4649:2002 standard. Cold water absorption was measured in compliance with the PN-EN ISO 62:2008 standard. The measurement of length and longitudinal shrinkage of the injection molded parts was made according to the procedures formulated by ISO 2944:2005. Heat deflection temperature (HDT) and Vicat softening point were measured using the CEAST HV3 from INSTRON CEAST Division. The temperature measurements were made in compliance with the procedures described by two standards: PN-EN ISO 75 (HDT) and PN-EN ISO 306 (Vicat). 


\section{Results and discussion}

The results of measurements and calculations served for making diagrams illustrating the effect of a given filler type and content on the longitudinal shrinkage, normal density, cold water absorption, abrasive wear, heat deflection temperature and Vicat softening point of the modified lowdensity polyethylene. The presented mean values were calculated from 10 measurements. The above relationships are illustrated in Figures 1 through 6.

The relationship of longitudinal shrinkage versus filler type and content is shown in Figure 1. With increasing the content of wheat bran, the value of longitudinal shrinkage decreases the shrinkage of the polyethylene filled with the highest tested wheat bran content is $2.15 \%$, which means it is by $0.23 \%$ lower than that of the unfilled polyethylene. The longitudinal shrinkage of the polyethylene filled with pumpkin seeds decreases with increasing the filler content; however, these values are still higher compared to that of unfilled polyethylene. The addition of 5\% wt. of pumpkin seed hulls results in a decrease in the shrinkage value from $2.38 \%$ to $2.73 \%$; for the highest tested content of this filler (i.e., $15 \%$ wt.), the longitudinal shrinkage of the polymer is $2.53 \%$.

The literature of the subject reports that the addition of powdered fillers leads to a decrease in processing shrinkage and its stabilization. The higher the content of a filler which does not generate any significant dimensional change in a processing temperature range, the higher the dimensional stability of the molded piece is $[6$, 16]. The above finding agrees with the observed variations in the longitudinal processing shrinkage of the polyethylene filled with wheat bran, i.e., the higher the filler content is, the lower the value of processing shrinkage. This trend is also observed for the polyethylene filled with pumpkin seed hulls; nevertheless, despite the decrease, all shrinkage values of the filled polyethylene are higher than the longitudinal shrinkage of the unfilled polyethylene.

The relationship between density of the tested polymer and the filler type and content is illustrated in Figure 1. On filling the polyethylene with the lowest tested content of wheat bran, the density decreases from $963 \mathrm{~kg} / \mathrm{m} 3$ to $796 \mathrm{~kg} / \mathrm{m} 3$, which amounts to a decrease to $82.6 \%$ of the initial value. Further increase in the bran content does not result in a further decrease in the density

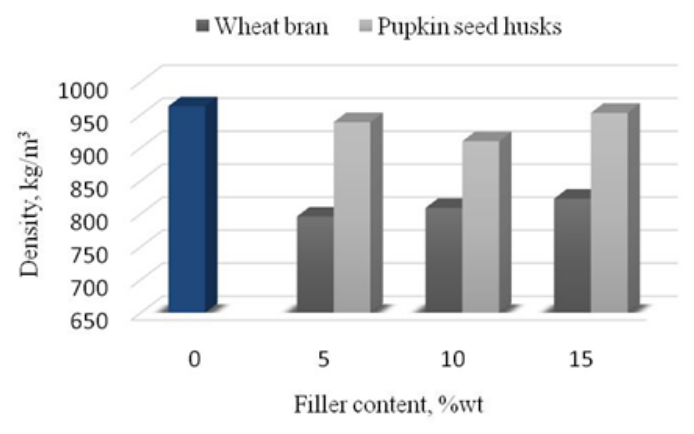

Fig. 1. Longitudinal shrinkage versus filler content

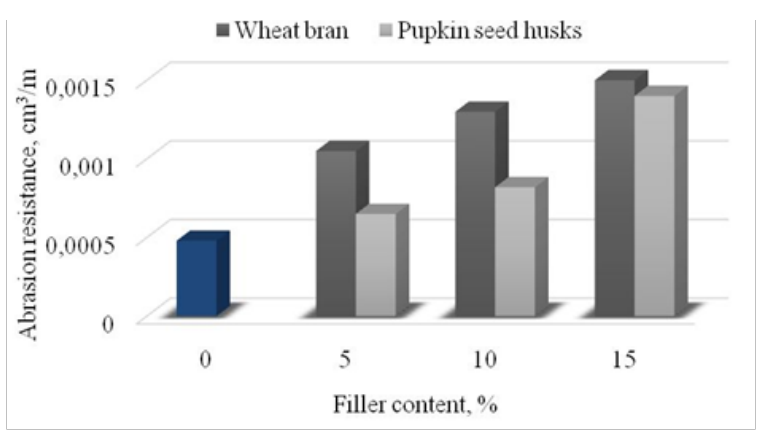

Fig. 2. Abrasion resistance versus filler content

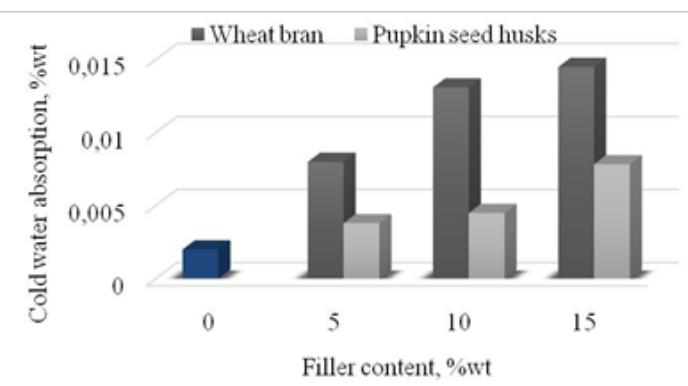

Fig. 3. Cold water absorption versus filler content

of the polyethylene; on the contrary, the density gradually increases and reaches $823 \mathrm{~kg} / \mathrm{m} 3$ for a $15 \%$ wt. content of wheat bran. The addition of $5 \%$ content of pumpkin seed hulls led to a decrease in the density of the polymer by $24 \mathrm{~kg} / \mathrm{m} 3$ compared to the density of the unfilled polyethylene. On adding 10\% wt. of this filler the density decreases to $910 \mathrm{~kg} / \mathrm{m} 3$, while with $15 \%$ wt. of pumpkin seed hulls, the density of the filled polyethylene increases up to $953 \mathrm{~kg} / \mathrm{m} 3$, i.e., it is by $10 \mathrm{~kg} / \mathrm{m} 3$ lower than that of the unfilled LDPE.

The observed changes in density are due to the fact that the density of the tested fillers is lower than that of polyethylene. The diagrams demonstrate that the density of LDPE is slightly higher than that of pumpkin seed hulls, whereas wheat bran has a density which is almost three 


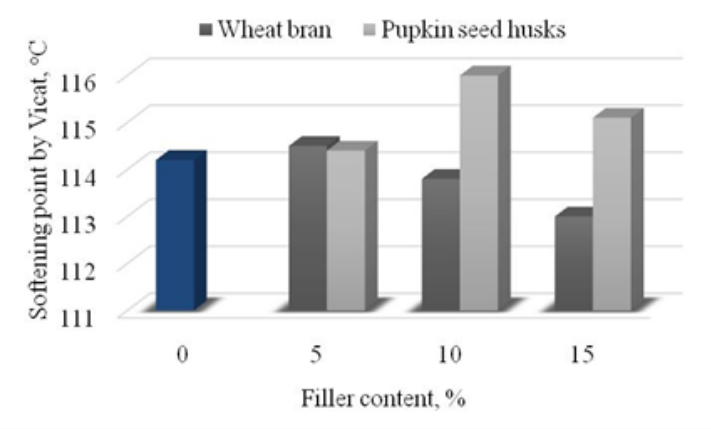

Fig. 4. Vicat softening point versus filler content

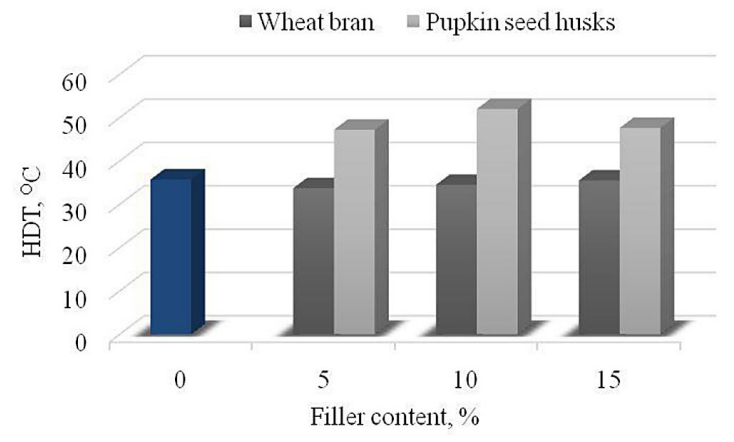

Fig. 5. Heat deflection temperature versus filler content

times lower (approx. $350 \mathrm{~kg} / \mathrm{m} 3$ ) [19] than that of the polymer matrix. As a result, a significant decrease in density can be observed after the addition of $5 \%$ filler content. It is, however, difficult to account for the subsequent increase in the density of the polyethylene filled with wheat bran and pumpkin seed hulls alike. An increase in the content of a filler characterized by a lower density than that of the polymer matrix should lead to a reduced density of the entire polymer composition. This may be due to variations in processing shrinkage, which are shown in Figure 1. The higher the shrinkage value is, the higher the density.

The relationship of abrasion resistance versus filler type and content is illustrated in Figure 2. The resistance to abrasion increases regardless of the type of filler used. The increase in the value of this parameter in the entire tested range of wheat bran content is equal to $0.00152 \mathrm{~cm} 3 / \mathrm{m}$, which is $216 \%$ of the initial value. The abrasion resistance of the specimens containing pumpkin seed husks increases to $0.00140 \mathrm{~cm} 3 / \mathrm{m}$ with the $15 \%$ content of this filler, which makes $191 \%$ of the initial value. The observed decrease in the abrasion resistance is probably due to the removal of the natural filler particles from the polymer matrix [1]. Being foreign particles in the polymeric material structure, wheat bran and pumpkin seed hulls have weak- ened the matrix cohesion force. Their presence could also lead to the occurrence of microckracks and the formation of relatively large material losses in the tested polymer compositions. The numerical results indicate that the addition of the natural fillers to the tested polymer results in a significant decrease in its abrasion resistance.

The results of cold water absorption of the injection molding with different contents of the tested fillers are shown in Figure 3. Addition of the natural fillers leads to an increase in the polymer's water absorbing capacity. Cold-water absorption of primary high-density polyethylene is $0.002 \%$ wt. and the addition of even the lowest wheat bran content $(5 \%)$ results in a higher water absorption of the molded pieces. With increasing the content of this filler, water absorbing capacity of the specimens increases, too. Similar observations were made for the polymer filled with pumpkin seed hulls.

Cellulose and lignin, two main components of the natural fillers used in this study, are composed of glucose residues containing polar hydroxyl groups that are highly interactive with water. The resulting hydrophilic properties mean that wheat bran and pumpkin seed hulls can absorb water from the environment [5]. The increase in water absorption was reported in the study [15], which investigated low-density polyethylene filled with rice bran.

Figure 4 shows the relationship between the Vicat softening pont and the type and content of the tested fillers. The addition of the wheat bran to the matrix of the low-density polyethyle described by the Vicat softening point of $114.2^{\circ} \mathrm{C}$ leads to a slight decrease in this parameter to $113^{\circ} \mathrm{C}$ for the highest tested content of this filler. Compared to the unfilled LDPE, the Vicat softening point of the polyethylene filled with pumpkin seed hulls increased to $116.2^{\circ} \mathrm{C}$ for the $10 \%$ wt filler content and to $115.1^{\circ} \mathrm{C}$ for the $15 \%$ wt filler content.

There is no specific rule that could be formulated to describe the effect of powdered fillers on Vicat softening point. Variations in this parameter depend on the type of filler and its interaction with the polymer matrix. Some fillers cause an increase in this Vicat softening point of polyethylene compared to that of the unfilled plastic while others make it decrease. In the analyzed case, it is difficult to speak of the effect of filler on Vicat softening point due to the fact that the percentage variations in this parameter are not higher than $1 \%$ of the initial value. 
The relationship of heat deflection temperature versus filler content is shown in Figure 5. The heat deflection temperature of the tested injection moldings tends to decrease with increasing the content of wheat bran. The lowest heat deflection temperature of the molded parts is observed on adding 5\% wt. of this filler and it is $33.7^{\circ} \mathrm{C}$, which represents a $5.6 \%$ decrease in the initial value. On adding the pumpkin seed hull filler, the HDT value first increases, only to decrease afterwards. The addition of $10 \%$ wt. of this filler leads to an increase in the heat deflection temperature by almost $45.65 \%$ compared to the initial value. The decrease in the HDT value of the specimens filled with bran wheat is probably caused by poor adhesion between the filler particles and the polymer matrix.

\section{CONCLUSIONS}

The results of the analysis of longitudinal shrinkage modifications indicates that increasing the filler content leads to a reduction in the processing shrinkage of the injection molded parts. With increasing the filler content in the plastic, longitudinal shrinkage significantly decreases while the dimensional accuracy of the molded parts increases, which considerably contributes to the improvement of their manufacturing quality and functionality.

The results show that the abrasion wear of the polymer filled with wheat bran and pumpkin seed hulls is higher, which probably results from the increase in the value of friction factor.

Compared to the unfilled polymer, water absorption of the filled polymer is several times higher. Consequently, it may be difficult to use such materials in applications exposed to moisture.

The Vicat softening point results do not indicate that the increase in the wheat bran and pumpkin seed hulls contents has any effect on the value of this parameter. Nonetheless, the results unambiguously demonstrate that the addition of different contents of pumpkin seed hulls to the tested low density polyethylene leads to the increase in the heat deflection temperature, which increases the temperature range for using products with such additives.

Wheat bran is an effective natural filler for polymeric materials in the injection molding process. Although this natural filler does not significantly affect the polymer's resistance to external factors such as temperature, water or abrasive wear, it considerably reduces the product weight (due to its low density), decreases production costs (wheat bran is usually a technological waste material in food production) and can accelerate the potential degradation time of the filled polymer blend.

\section{REFERENCES}

1. Chomiak M. and Stabik J. Wpływ cząstek węgla kamiennego na twardość i ścieralność polimerowych materiałów gradientowych. Przetwórstwo Tworzyw, 6, 2013, 582-591.

2. Chou T. Structure and Properties of Composites. Materials Science and Technology, Volume 13: Structure and properties of composites. VCH Verlagsgesellschaft, Weinheim 1993.

3. Chruściel J., Leśniak E. and Fejdys M. Carbofunctional silanes and polysiloxanes. Part I. Applications of carbofunctional silanes. Polymer, 10, 2008, 709-716.

4. Czupryński B., Liszowska J. and Sadowsa-Paciorek J. Modyfikacja sztywnej pianki poliuretanowopoliizocyjanurowej wybranymi napełniaczami proszkowymi. Polimery, 2, 2008, 133-137.

5. Essabir H., Hilali E. and others. Mechanical and thermal properties of bio-composites based on polypropylene reinforced with Nut-shells of Argan particles. Materials\&Design, 49, 2013, 442-448.

6. Fisher J. M. Handbook of molded part shrinkage and warpage. Plastic Design Library, William Andrew Inc., Norwich 2003.

7. George J., Kumar R. and others: Rice bran-filled biodegradable low-density polyethylene films. Development and characterization for packaging applications. Journal of Applied Polymer Science, 5, 2006, 4514-4522.

8. Hassan A., Salema A. A. and others. A review on oil palm empty fruit bunch fiber-reinforced polymer composite materials. Polymer Composites, 31 , 2010, 2079-2101.

9. Jagadish R. S., Raj B. and Asha M. R. Blending of low-density polyethylene with vanillin for improved barrier and aroma-releasing properties in food packaging. Applied Polymer, 113, 2009, 3732-3741.

10. Katz H. and Milewski J. Handbook of fillers for plastics. Van Nostrand Reinhold, New York 1987.

11. Khait K. and Carr S.H. Solid-State Shear Pulverization. Technomic Publishing Company Inc. Lancaster, PA, USA 2001.

12. Murali Mohan Rao K., Mohana Rao K., Ratna Prasad A. V. Fabrication and testing of natural fibre composites: Vakka, sisal, bamboo and banana. Materials\&Design, 31, 2010, 508-513. 
13. Narkis M. and Rozenzweig N. Polymer Powder Technology. John Wiley \& Sons New York 1995.

14. Nuraya A. S., Baharin A. and Azura A. R. Influence of banana stem powder on knotty tear behaviour of prevulcanised natural rubber latex composite films. Plastics, Rubber and Composites: Macromolecular Engineering, 44, 2015, 265-272.

15. Rattanasom N., Saowapark T. and Deepprasertkul C. Reinforcement of natural rubber with silica/carbon black hybrid filler. Polymer Testing, 26, 2007, 369-377.

16. Rosato D. V. and Rosato M. G. Injection Molding Handbook. Kluwer Academic Publisher, Norwell 2000.

17. Rothon R. Particulate-Filled Polimer Composites,
Second Edition. Rapra Technology Limited, Shawbury 2003.

18. Sterzyński T. and Kubczak M. Wysokonapełnione kompozyty polietylen/mata ołowian baru do zastosowań w bipolarnych akumulatorach kwasowo-ołowiowych. Polimery, 2, 2006, 150-153.

19. Stevenson L., Phillips F. and others. Wheat bran: its composition and benefits to health, a European perspective. International Journal of Food Sciences and Nutrition, 63, 2012, 1001-1013.

20. Tor-Świątek A., Garbacz T., Jachowicz T.: Quantitative assessment of the microscopic structure of extruded and injected low-density polyethylene modified with microspheres by image analysis. Cellular Polymers, 2, 35, 2016, 67-84. 